University of Wollongong

Research Online

Faculty of Social Sciences - Papers (Archive) Faculty of Arts, Social Sciences \& Humanities

2020

Project-based learning groups of friends and acquaintances: The role of efficacy beliefs

Jose Hanham

John McCormick

University of Wollongong, johnmcc@uow.edu.au

Adam Hendry

Follow this and additional works at: https://ro.uow.edu.au/sspapers

Part of the Education Commons, and the Social and Behavioral Sciences Commons

Research Online is the open access institutional repository for the University of Wollongong. For further information contact the UOW Library: research-pubs@uow.edu.au 


\title{
Project-based learning groups of friends and acquaintances: The role of efficacy beliefs
}

\begin{abstract}
This school-based study explored the role of collective and proxy efficacy beliefs in the performances of project-based learning teams comprising friends and acquaintances. Participants were 162 male students in Grade 8 who attended a Catholic high school, located in Sydney, Australia. Students were organized into 20 acquaintance groups and 21 friendship groups. Each group comprised 4 students who were completing project-based learning assignments in Geography, Religious Studies, and English. Data were self-reports and teacher-assessed group performance scores. Data collection occurred three times over a five-week period. Multilevel modeling was used to examine relationships between variables in the study. Statistically significant interactions involving group type, collective efficacy, and proxy efficacy were identified in Geography and Religious Studies. Implications are that it may be advantageous for teachers to assign students to friendship groups, provided they nurture collective efficacy, and that proxy efficacy may negatively affect group performance, depending on the context.
\end{abstract}

\section{Disciplines \\ Education | Social and Behavioral Sciences}

\section{Publication Details}

Hanham, J., McCormick, J. \& Hendry, A. (2020). Project-based learning groups of friends and acquaintances: The role of efficacy beliefs. Journal of Educational Research, 113 (2), 133-144. 
Running Head: PROJECT-BASED LEARNING, FRIENDS, EFFICACY BELIEFS

Project-based learning groups of friends and acquaintances: The role of efficacy beliefs 


\begin{abstract}
This school-based study explored the role of collective and proxy efficacy beliefs in the performances of project-based learning teams comprising friends and acquaintances. Participants were 162 male students in Grade 8 who attended a Catholic high school, located in Sydney, Australia. Students were organized into 20 acquaintance groups and 21 friendship groups. Each group comprised 4 students who were completing project-based learning assignments in Geography, Religious Studies, and English. Data were self-reports and teacher-assessed group performance scores. Data collection occurred 3 times over a fiveweek period. Multilevel modeling was used to examine relationships between variables in the study. Statistically significant interactions involving group type, collective efficacy and proxy efficacy were identified in Geography and Religious Studies. Implications are that it may be advantageous for teachers to assign students to friendship groups, provided they nurture collective efficacy, and that proxy efficacy may negatively affect group performance, depending on the context.
\end{abstract}




\section{Introduction}

Historically, whole-class teaching, which refers to teacher-led instruction of an entire class, has been the dominant mode of instruction in classrooms (Galton, Hargreaves \& Pell, 2009). As a consequence, it appears that relatively few studies have been carried out in school settings where working in groups is the predominant mode in which teaching and learning takes place (Baines, Blatchford \& Webster, 2015). This study was carried out in a single high school in Sydney, Australia because it was known that project-based learning was the main mode of instruction for students in the junior high school years, grades 7 to 10 , and in which most teaching and learning was in project groups. The nature of project-based learning in the school is consistent with project-based learning approaches described by proponents (see Savery, 2006), i.e., with projects extending over a 5 to 10 -week period with organised and scaffolded learning activities designed to support groups of students (usually 3 to 5) to achieve desired outcomes within certain prescribed boundaries, and with a summative task as the defined 'end product'. At the beginning of each project, students were provided with detailed assessment rubrics. Students were assessed, both individually and as part of a group, in associated content knowledge and skills in each project. Individual assessment through formative tasks occurred at the mid-point of each group assignment, and the group assessment occurred through a summative task, submitted at the end of a 5 or 10-week period. For a more detailed discussion of how project-based learning is implemented at the school where this study was conducted, please see Hendry, Hays, Challinor and Lynch (2017).

A perennial dilemma for teachers when implementing group-based activities, is whether to assign students to work with friends or acquaintances (Hanham \& McCormick, 2008, 2009, 2018; Mitchell, Reilly, Bramwell, Solonsky, \& Lilly, 2004; Swenson \& Strough, 
PROJECT-BASED LEARNING, FRIENDS, EFFICACY BELIEFS

2008). We were interested in whether the assignment of students to friendship or acquaintance groups was related to the performance of these groups on project-based learning assignments. We were also interested in relationships between social-cognitive variables, specifically, collective efficacy and proxy efficacy, and the performance of friendship and acquaintance groups on project-based learning assignments. The current literature on projectbased learning has identified the need for research to explore the roles of students' efficacy beliefs in project-based learning settings (Hendry et al., 2017).

\section{Friendship and acquaintance groups}

Friendship groups are voluntary relationships anchored by a shared history, mutual regard, and strong interpersonal connections of group members. Acquaintance groups generally involve people who have limited interpersonal knowledge and/or previous direct contact with others in the group (Jehn \& Shah, 1997). The decision to allocate students to friendship or acquaintance groups is likely to be pertinent when project-based learning is the main mode of instruction, given that students generally spend most of their time working on group-based activities.

Friendship plays a critical role in child and adolescent development (Newcomb \& Bagwell, 1995; Rubin, Bukowski, \& Parker, 2006), having direct and indirect influences on students' goals, behaviors, academic performances, adjustment, and engagement in school (Berndt, 2002; Barry \& Wentzel, 2006; Wenztel, Barry \& Caldwell, 2004). A recent metaanalysis, which examined relationships between friendship and academic outcomes in school settings (Wentzel, Jablansky \& Scalise, 2018), found that students working with friends was positively associated with use of cognitive skills (e.g., problem-solving) and academic performance (e.g., achievement scores). These findings support long-held notions (see Hartup, 1996; Hartup \& Stevens, 1997) that friendship groups can provide an important 
context for the development of students' problem-solving skills and academic-achievement capabilities.

Friends generally have a more extensive shared history and know each other more intimately than non-friends (Ladd \& Emerson, 1984). Consequently, friends may be expected to have a better grasp of each other's prior knowledge and perspectives than non-friends. Compared with acquaintances, friends also tend to feel more comfortable with each other (Newcomb \& Bagwell, 1995), exhibit a greater willingness to offer suggestions (Hartup, 1998), and build on each other's ideas (Azmitia \& Montgomery, 1993). Furthermore, it has been suggested that criticisms offered by friends during group discussions generally are likely to be more appropriate than those proffered by non-friends (Zajac \& Hartup, 1997), with friends more inclined to use negotiation and disengagement to resolve conflicts than nonfriends (Newcomb \& Bagwell, 1995). Effectively sharing, building, and critiquing ideas, and resolving conflicts are key components of successful group work (Webb \& Palincsar, 1996). Importantly, they are also critical in helping students consolidate and restructure prior knowledge (Webb \& Mastergeorge, 2003).

Although friends appear to afford academic benefits, it is important to acknowledge that friendship groupings can and do have problems and may not always be superior to acquaintance groupings. Friendship can vary in quality (Berndt, 2002); not all groups of friends are oriented toward academic learning and engagement in school. Some friendships can be plagued by dysfunction, dominance and conflict (Burk \& Laursen, 2005). In terms of performance in group-based learning tasks, some studies (e.g., Azmitia \& Montgomery, 1993; Miell \& McDonald, 2000) have found that friends generally outperform acquaintances, although, others have not (e.g., Berndt, Perry \& Miller, 1988). Moreover, it appears that performance differences between friendship and acquaintance groups may vary according to 
task types (Chung, Lount, Park \& Park, 2018). To illustrate, a recent meta-analysis (Chung et al., 2018) compared the performances of friendship and acquaintance groups, involving both school-based and workplace studies, and found that friends generally outperformed acquaintances on maximizing tasks (e.g., coming up with as many ideas as possible), although, friends did not outperform acquaintances for optimizing tasks (e.g., producing correct answers).

\section{Efficacy beliefs}

Many factors may be identified in the mixed findings concerning the performances of friends and acquaintances on group-based tasks. Indeed, there is still much to unpack concerning the motivational processes that underlie how students approach working with their friends and acquaintances. Hanham \& McCormick $(2008,2009)$ have suggested that students' self-efficacy beliefs for working in groups may be related to students' attitudes to cooperating with friends and acquaintances, as well as group behaviors such as generating and critiquing ideas (Hanham \& McCormick, 2018). Self-efficacy, which refers to individuals' beliefs about their capabilities of executing and organising courses of action to secure desired outcomes, is a key component of Bandura's (1997, 2001) Social Cognitive Theory (SCT). This study seeks to build on this line of research through exploring the possible roles of two other categories of efficacy beliefs: collective efficacy and proxy efficacy.

\section{Collective Efficacy}

A key tenet of SCT is that efficacy beliefs are fundamental to the exercise of human agency, which refers to actions carried out intentionally (Bandura, 1997). There are different modes by which humans can exercise agency, including direct personal agency, which involves selfefficacy. Humans can also exercise agency in concert with others; this is known as collective 
agency. The effectiveness of collective agency is underpinned in large part by collective efficacy. Arguably the most common conceptualisation of collective efficacy is that it represents group members' shared beliefs in their perceived collective capabilities to achieve desired outcomes (Bandura, 1997). Although less common, collective efficacy can also be conceptualized as a group member's personal belief about the group's capability to attain desired outcomes (Alavi \& McCormick, 2018).

Similar to self-efficacy, collective efficacy is domain/task specific and emerges over time in groups in response to inputs such as feedback and the perceived characteristics of group members (Goncalo, Polman \& Maslach, 2010). Collective efficacy is assumed to be related to the choices made by groups, the amount of effort that groups exert on tasks, and persistence when groups encounter difficulties (Bandura, 2000). Several meta-analyses (Gully, Incalcaterra, Joshi \& Beaubien, 2002; Stajkovic, Lee \& Nyberg, 2009) found that collective efficacy predicted group performance. Collective efficacy has also been linked to group goals (Goddard, Hoy \& Hoy, 2004) and group cohesion (Wang \& Hwang, 2012). Although collective efficacy beliefs have been associated with a range of positive outcomes, some research (e.g., Goncalo et al., 2010), has suggested that high levels of collective efficacy in early phases of group assignments may have a negative impact on the eventual overall performance of groups. According to Concalo et al. (2010) high collective efficacy can act as a restraint on group processes such as group conflict, which are ultimately, important for successful group performance.

As an emergent group-level state, there are a number of sources of information, which may shape the collective efficacy beliefs of groups. Mastery experiences are considered the most influential source of efficacy beliefs. Groups that have had previous successes are likely to have strong collective efficacy, whereas groups with a record of failures are likely to have 
weak collective efficacy (Bandura, 1997). Collective efficacy can also be influenced through vicarious experiences in which groups observe the successes and failures of other groups which share similar characteristics (e.g., ability levels). Social persuasion can also be a source of collective efficacy, whereby groups are provided with appraisals of their capabilities from influential sources, for example, managers in workplace contexts and teachers in school settings. Positive evaluations from influential sources will likely boost collective efficacy; on the other hand, negative assessments will likely reduce collective efficacy. The affective states of groups can also impact collective efficacy. In striving to attain desired outcomes, many groups, from time to time, will be confronted with a range of stressors, which impact the mood of the group. Groups that respond positively to stressors are likely to have enhanced collective efficacy. Alternatively, groups which do not respond well to stressors are likely to have diminished collective efficacy.

\section{Proxy efficacy}

In addition to being able to exercise agency directly and collectively, individuals can also exercise agency indirectly, through the assistance of other entities, which can be categorised as proxies (Alavi \& McCormick, 2016; Hanham, Ullman, Orlando \& McCormick, 2014). There are a number of reasons for people to engage proxy agents. For instance, people may not possess the necessary knowledge and skills to act intentionally by themselves to obtain desired outcomes. This can be seen in legal matters, where people often employ a lawyer as a means to exercise their legal rights. Lawyers carry out various tasks on behalf of clients, such as representing them in court proceedings in order to secure favourable judicial decisions. In financial matters, people often hire accountants to prepare and submit tax statements on their behalf. 
The nature and structure of a particular environment may necessitate engagement with proxies. An example of this is a group assignment in which group members are designated specific roles to fulfil on behalf of the group. As stated by Hare (1994), a group role is a "position in a group (a status) with rights and duties toward one or more other group members" (p. 434). That is, fulfilling group roles involves an obligation to serve the needs of fellow group members and the group as a whole. For instance, a group member designated as the organizer of the group may be responsible for arranging milestones that need to be met, and ensuring that fellow group members are given timely reminders about these milestones. Carrying out such tasks on behalf of the group is important, as it should help other group members function more effectively in their roles as they are being made aware of when they need to complete specific tasks.

Sources of proxy efficacy are likely to be broadly similar to those of collective efficacy and self-efficacy, although the dynamics could be different. In the development of proxy efficacy in group work settings, members of groups are likely to form proxy efficacy judgments based on the successes and failures of their fellow group members carrying out specific roles. In the absence of direct experience with the fellow group members, proxyefficacy may still be formed through previous observations of fellow group members carrying out tasks in classrooms, similar to those they were expected to perform during a particular group assignment. Proxy efficacy can also be shaped through social persuasion. For example, a reputable teacher or trusted friend may inform a group member about the capabilities of certain other group members in carrying out their roles. Positive evaluations likely enhance proxy efficacy, whereas negative appraisals likely lower proxy efficacy. Observations of the affective states of fellow group members may also impact proxy efficacy beliefs. Proxy efficacy for fellow group members who are observed to be anxious during group work 
activities may diminish. In contrast, proxy efficacy for group members who are observed to be 'comfortable' may be increased.

\section{Research questions}

Several research questions guided this study. First, there are mixed findings concerning the performances of friendship and acquaintances in school settings. Moreover, it appears that there has not been empirical research exploring the performance differences of friendship and acquaintance groups in school settings in which project-based learning is the mode of instruction. Thus, the first research question is

RQ1. Are there statistically significant differences in the performances of friendship and acquaintance groups working on group assignments in a school setting in which project-based learning is the principal mode of instruction?

Because project-based learning is the main mode of instruction for the participants in this study, students were likely to have spent considerable time working in groups with their classmates, and therefore to have developed shared beliefs about the capabilities of the project teams in which they worked (i.e., collective efficacy), and beliefs about the capabilities of individual classmates to carry out specific roles on behalf of their teams (i.e., proxy efficacy). As students worked in project groups for five weeks, the following research question is

RQ2. How are collective efficacy and proxy efficacy beliefs related to the performances of the friendship and acquaintance groups in this study?

We were also interested in investigating possible interaction effects involving the key variables in the study. The final research question is 
PROJECT-BASED LEARNING, FRIENDS, EFFICACY BELIEFS

RQ3. Are there statistically significant interaction effects involving collective efficacy, proxy efficacy, and group type (friends/acquaintances)?

\section{Method}

\section{Sample}

The sample comprised 21 friendship and 20 acquaintance groups completing group assignments in Religious Studies, Geography, and English at a Catholic Boys High School, in Sydney Australia. These subjects were chosen by the participating school; we considered it pragmatic, but also ethically important, to take account of the school's curriculum requirements. The total number of groups $(n=41)$ is above the minimum needed (i.e., 30$)$ for running multilevel analysis with fixed parameters only (Stegmueller, 2013). Each group comprised 4 male students $(\mathrm{N}=164)$. Mean age $=13.54$ years and $\mathrm{SD}=.55$.

\section{Measures}

A questionnaire, titled "Efficacy beliefs and Project-Based Learning" was developed for this study. There were four versions of the questionnaire, with each version corresponding to a specific role for which group members were randomly allocated (i.e., coordinator, video producer, storyboard developer, project developer). Further discussion concerning the nature of roles is provided in the next section. Collective efficacy and proxy efficacy beliefs are domain/task-specific constructs and according to Bandura's (2006) guidelines, efficacy items "must be tailored to the particular domain of functioning that is the object of interest" (p. 308). In accordance with this advice, measures of collective efficacy and proxy efficacy were developed in line with the parameters of the study. Ten items measured collective efficacy, with these items designed to capture group members' beliefs about their groups' capabilities for performing tasks such as "developing a plan for the group project" and "collaborating 
effectively". The collective efficacy items were measured on an 11-point percentage scale ranging from $0 \%$ not at all confident to $100 \%$ completely confident. Proxy efficacy items were based on the tasks for each specific group role. Ten items measured proxy efficacy for the coordinator, including, "coordinating other group members to perform their tasks" and "directing group discussion". Ten items measured proxy efficacy for the video producer, including, making sure "the video follows the storyboard" and "using different camera angles to improve the quality of the video". Nine items measured proxy efficacy for the storyboard developer, including, "developing the group's ideas into a storyboard" and "making changes to the storyboard based on feedback from the group". Seven items were used to measure proxy efficacy for the project developer including, "reporting accurately on the group's progress to teachers" and "bringing together the group's research into a portfolio". For each role, group members were asked to rate their fellow group members' capabilities for successfully carrying out tasks for their specific roles. All of the proxy efficacy items were measured on an 11-point scale, ranging from $0 \%$ not at all confident to $100 \%$ completely confident”.

\section{Descriptions of the group roles}

The names and descriptions of roles are identical to those employed by the school. The Coordinator was responsible for managing the group and acting as the group spokesperson, mediator, negotiator, and arbitrator to resolve interpersonal problems or conflicts as well as the main liaison with teachers. The Video Producer was responsible for the audio-visual elements of the project, including equipment, recording, layout, and sound mixing through selected video editing platforms. The Storyboard Developer was responsible for the construction, development, and maintenance of the video storyboard, and editing the script. Lastly, the Project Developer was responsible for the planning, sequencing and allocation of 
tasks as well as the day-to-day running of the group including the maintenance of the group's online calendar, adherence to the group's contract, and meeting deadlines.

\section{Procedures}

Protocols for the study were approved by the Human Research Ethics Committee at Western Sydney University and the Diocese in which the school was located. An information package was given to students in grade 8 , which included an invitation and description of the study, an outline of what involvement would entail, and statements explaining that participation in the study was voluntary and they were free to withdraw anytime, without penalty. Those students, and their parents, who decided to participate gave written informed consent.

\section{Sociometric Mapping}

Sociometric mapping (Finegold \& Eilam, 1995; Henrich, Kuperminc, Sack, Blatt \& Leadbeater, 2000) was employed to identify friendship and acquaintance clusters. Each student was asked to nominate, in order, up to five students he regarded as close friends, and to nominate fellow students, in no particular order, whom they did not regard as close friends. The researchers deliberately chose not to require ranking to avoid possible priming of antagonistic thoughts about fellow students. In line with Henrich et al.'s (2000) approach, first, 21 friendship groups, comprising reciprocated friendships, were identified. Then, remaining students were sorted into 20 acquaintance (not-close friends) groups. Students were not made aware that they were being allocated to friendship and acquaintance groups.

\section{Projects}

In line with the curriculum requirements of the school, the study focused on project-based learning in three subjects. Data were collected whilst students undertook three stand-alone (non-integrated) five-week projects in three different disciplines: Geography, English and 
Religious Studies. All groups, with the same composition completed all three projects in the same roles. Students were initially randomly assigned their roles within the groups which they then carried out/through all of the three projects. All three projects were run concurrently in timetabled lessons throughout the 5-week period - the duration of each project. As a project-based learning school, this is routine. In that period, students had a total of 13.5 periods (100 minutes per period) for each course equating to 22.5 contact hours over the life of the project. These lessons are mostly distributed over a fortnightly cycle (2.5 hours one week and 2 hours the following week) but not necessarily in the same period during the three-period school day.

Whilst undertaking different projects derived from varying content and syllabus outcomes, the summative task (or 'end-product') for each of the three projects required groups to produce a short video whilst fulfilling four different predetermined roles and thereby utilizing similar skills (e.g., video producing, storyboarding) to complete the project. Two teachers, subject matter experts, from respective disciplines (Religious education, Geography and English) marked all group videos in their respective areas of expertise. As is practice at the school, when discrepant marks allocated by teachers lie in different performance bands (i.e. basic, competent and advanced), these differences are resolved by discussion between the markers or via moderation by the head of faculty. A rubric was designed for each of the three projects. However, whilst each one addressed specific content from each knowledge domain, criteria dealing with the video production were consistent across all three rubrics (see appendix A). A short description of each project and the associated problem-solving tasks are presented below.

\section{Globalization Project (Geography)}


Students explored how the process of globalization had transformed global communities and created significant opportunities as well as great challenges and disparity socially, technologically, and economically. In addition, students investigated the various strategies that had been implemented by government and non-government organizations to minimize or reduce the impacts of globalization on both global communities and the environment. The summative task was a short video of a panel discussion (with group members as panelists) concerning the origins, benefits and burdens of globalization, and its impact on relationships between developed and developing countries in terms of access to education, food, health, shelter, natural resources, and quality of life.

\section{People of the Covenant Project (Religious Studies)}

Students investigated the concept of the covenant that Judaeo-Christian peoples made with their god. The summative task for this project was a short video of a contemporary story depicting how the people of the covenant live their lives and highlighting its importance to them. More specifically, students were required to make a video that uses illustrations, words, images and other media to convey the message. Over the course of this project, students were challenged in terms of their filmmaking ability and conceptual understanding of the nature of religion and the notion of the covenant.

\section{English Cultural Poetry}

Students explored how different poets from different cultures had utilized poetry to convey meaning and understanding of their traditions and customs, and how they expressed their individual cultural identities. Moreover, an important outcome of this project was the fostering of intercultural understanding. Understandably, the first step for students was to explore poetical techniques used to convey messages, how to deconstruct and analyse poetry through critical poetic analysis, and how to effectively and imaginatively use various poetic 
techniques and structures when composing their own poems including haikus and slam poems. The summative task of this project was a video promoting cultural awareness and diversity through poetry. This involved the creation of a group poem about a chosen culture(s) that is not their own, expressed through video.

\section{Video production in projects}

For all projects, a number of non-compulsory tutorials and scaffolded activities were available for each student in relation to his specified role within the group. Other specialized tutorials such as whiteboard videos were also available.

\section{Administration of surveys}

Efficacy beliefs are malleable and can change over time (Bandura, 1997). Because the projects were to run for a period of 5 weeks, it was considered important measure efficacy beliefs over several intervals. Survey data were collected just after of the commencement (end of week 1), mid-point (end of week 3) and completion (end of week 5) of the projects.

\section{Analyses and results}

\section{Exploratory factor analyses}

Exploratory factor analysis (EFA) was employed because of the sample size. Principal axis factoring with oblimin rotation was separately applied to the items measuring collective efficacy and proxy efficacy for each of the roles. The criteria for extraction were eigenvalues greater than one, scree plot, and most importantly, theoretical considerations.

EFA of the collective efficacy items at times 1 and 3 identified single factors. However, EFA of the collective efficacy data collected at time 2, found that item 10, the 
group can resolve conflict constructively, loaded as a separate, single factor. To ensure comparability between measurement points, EFAs for the collective efficacy items at each measurement point were run again with item 10 removed from the analyses. Three collective efficacy factors (identical items), one for each measurement point were identified. In Table 1 below, the scale means, standard deviations and the ranges of the factor loadings are reported. In addition, as an estimate of reliability, we report McDonald's Omega ( $\omega$ ) (McDonald, 1999).

\section{INSERT TABLE 1 ABOUT HERE}

Proxy-efficacy was operationalised as a characteristic of the group, that is, group members making the estimations of other group members' capabilities in fulfilling their specific roles. Thus, in a group of four, there were three proxy efficacy scores for each role. The mean of the scores provided the proxy efficacy measure for each role.

EFAs of the proxy-efficacy items identified single factors for each of the four roles that were identical across the three measurement points. The ranges of the factor loading and Omega estimates are reported in Table 2 below.

\section{INSERT TABLE 2 ABOUT HERE}

\section{Multilevel Modeling}

As an initial step, fully unconditional variance decomposition models were estimated (see Table 3). All variables had statistically significant variance at the individual level. There was statistically significant variance at the group level for collective efficacy at all three time points. There was statistically significant variance at the group level at all three time points for proxy efficacy for the coordinator. Proxy efficacy for the storyboard developer and proxy efficacy for the project developer had statistically significance variance at the group level for 
times 2 and 3, though not at time 1. Proxy efficacy for the video producer only had statistically significant variance at the group level at time 2. Variation in statistically significant group variance at different time points for proxy efficacy for the different roles may be explained by the level of activity required for each role at each time point. The coordinator was required to be active at the outset, whereas other roles probably required greater activity at different points in the process.

\section{INSERT TABLE 3 ABOUT HERE}

The next step was generating level 2 variables: Means of individual level collective scores of each group member in each group were calculated. The means were then assigned to all members of the same group. Means of proxy efficacy at each time point, for each role, were calculated and assigned to all members of the same group. Pearson correlations of the level 2 variables are presented in Table 4.

\section{INSERT TABLE 4 ABOUT HERE}

Separate multilevel models were developed to assess the relationships between the group performance as dependent variable in Geography, Religious Studies, and English. However, all variables were at level 2. We adopted a hierarchical approach for model testing (Pedhazur, 1982). As group type, that is, whether groups comprised friends or acquaintances, was fundamental to the study, this variable was entered first as a dummy variable (acquaintances $=0$, friends $=1$ ). As an emergent property of groups, collective efficacy was entered next, followed by the group characteristic, proxy efficacy. Product terms (e.g., group type X collective efficacy at time 3) were entered last. The final models for each subject are presented in Tables 4 to 6 .

\section{Predictors of group performance in Geography}


In Table 5 multilevel models with group performance as the dependent variable in Geography are presented. Model 4 is the final model. Group type emerged as a statistically significant predictor of group performance in the final model, with friendship groups outperforming acquaintance groups.

\section{INSERT TABLE 5 ABOUT HERE}

There were several statistically significant interaction terms. These are depicted as regression lines in Figures 1 and 2. Figure 1 shows that for Geography when collective efficacy at time 3 was low, acquaintance groups generally scored higher in the summative tasks, but when collective efficacy was high, the friendship groups generally performed better on the summative task than acquaintance groups.

\section{INSERT FIGURE 1}

There was also a statistically significant interaction between group type and proxy efficacy at time 3. Figure 2 shows that when proxy efficacy was low, acquaintance groups generally scored higher than friendship groups on the summative task, but when proxy efficacy was high, friendship groups generally scored higher task. In Geography, the results suggest that collective and proxy efficacy beliefs were important for the performances of friendship groups.

\section{INSERT FIGURE 2 ABOUT HERE}

\section{Predictors of group performance in Religious Studies}

Multilevel models with group performance in religious studies as the dependent variable are presented in Table 6. In the final model, collective efficacy measures at times 1 , 2, and 3 were statistically significant predictors of group performance. For the final model, proxy efficacy measures at times 2 and 3 were statistically significant negative predictors of 
group performance; correlations in Table 3, show that the proxy efficacy measures were negatively correlated with group performance in Religious Studies.

\section{INSERT TABLE 6}

These results indicate that although groups' shared beliefs in their collective abilities to successfully carry out tasks (i.e., collective efficacy) are positively associated with performance scores for summative task in religious studies, positive beliefs about the capabilities of group members to fulfil their roles as part of the group (i.e., proxy efficacy), do not translate to higher scores on the summative task- in fact they are negatively associated with group performance.

There was a statistically significant interaction between group type and collective efficacy at time 3 . Figure 3 shows that when collective efficacy was relatively low at time 3 , acquaintance groups outperformed friendship groups. However, when collective efficacy was relatively high at time 3 , friendship groups outperformed acquaintance groups. This result is similar to that found for the summative task in Geography.

\section{INSERT FIGURE 3 ABOUT HERE}

There was a statistically significant interaction between group type and collective efficacy at time 2. Figure 4 shows that when collective efficacy was relatively low at time 2 , acquaintance groups outperformed friendship groups. However, when collective efficacy was relatively high at time 2, friendship groups outperformed acquaintance groups. Again, this appears to be a recurring pattern of in the interactions involving collective efficacy and group type. 
There was a statistically significant interaction between proxy efficacy and collective efficacy at time 3 (see Figure 5). When collective efficacy is low, low proxy efficacy groups generally outperformed high proxy efficacy groups. Similarly, when collective efficacy is high, low proxy efficacy groups generally outperformed high proxy efficacy groups.

\section{INSERT FIGURE 5 ABOUT HERE}

There was a statistically significant interaction between proxy efficacy and collective efficacy at time 2 (see Figure 6). When collective efficacy was low, low proxy efficacy groups generally outperformed high proxy efficacy groups. When collective efficacy was high, there was little difference in the performances of low and high proxy efficacy groups.

\section{INSERT FIGURE 6 ABOUT HERE}

\section{Predictors of group performance in English}

Multilevel models with group performance in English as the dependent variable are presented in Table 7. In the final model, there were neither statistically significant direct effects nor statistically significant interactions.

\section{INSERT TABLE 7 ABOUT HERE}

\section{Discussion and conclusions}

This study explored several aspects of project-based learning of groups comprised of either friends or acquaintances. Three research questions guided the study. RQ1 was concerned with whether there were statistically significant differences in the group performances of friendship and acquaintance groups. In answer to the first research question, there was a significant difference in the performances of friendship and acquaintances, but only in geography. One explanation for this result concerns the nature of the summative task used for the geography project, which was a filmed panel discussion. Arguably, a panel discussion 
could afford greater opportunity for interaction between group members regardless of their nominated role. Friendship may be a more salient factor for the summative task because it requires greater discourse between group members to prepare, deliver, and present a filmed panel discussion. Implicit in the task, group members were required to offer opinions, discuss, exchange ideas and build upon each other's contributions in order to prepare a script and to fulfil a role as a panellist with a particular perspective; and, like an actor in a play, each group member would also be aware of each other's lines. This, in turn, may favour friendship over acquaintance groups as research suggests that the generation and building of ideas occurs more readily among friends than among acquaintances (Azmitia \& Montgomery, 1993; Hartup, 1998). Although a recent meta-analysis (see Wentzel et al. 2018) found friendship groups in general performed better on academic achievement tasks than acquaintance groups, this was not a uniform finding across the three subjects in this study. This result mirrors previous mixed findings in some past studies (e.g., Berndt et al., 1988), which found no statistically significant differences in performances of friendship versus acquaintance groups.

RQ2 was concerned with how collective efficacy and proxy efficacy beliefs were related to the overall performances of the friendship and acquaintance groups. In terms of direct effects, collective efficacy measured at the beginning, mid-point and end-point of the Religious Studies project was positively associated with performance on the summative task for this subject. This positive association between collective efficacy and group performance is consistent with findings from studies on collective efficacy in organizational settings (Gully, et al., 2009; Stajkovic et al., 2009). This finding also aligns with emerging research in school-based settings, which have shown that collective efficacy can predict task performance for group activities (Khong, Liem \& Klassen, 2017). It is important to note that collective efficacy did not predict group performance for the final multilevel models in 
English and Geography. This result may suggest the importance of context when examining efficacy beliefs (McCormick, Alavi \& Hanham, 2015). Future research on efficacy beliefs in project-based learning settings may probe contextual factors (e.g., group allocated roles vs. teacher allocated roles) more deeply, for example, through interviews and/or observational analysis. It is also important to emphasise that other efficacy constructs, namely, self-efficacy

Whilst collective efficacy was positively associated with group performance in Religious Studies, proxy efficacy measured at the mid and end points of the project was negatively associated with group performance on the summative task in Religious Studies. As a possible explanation, it is likely that the higher the individual's proxy beliefs, the greater the agency individuals cede to the proxies, which could result in a diminution of their personal performances. Simply put, overconfidence in fellow group members' abilities likely leads to a lessening of their own efforts. The nature of the summative task and the subject itself may have also contributed to this result. Arguably, elements of religious studies are more abstract in nature (e.g. what is god?) which could have impacted the assessment of other group member's capabilities and depth of knowledge in the subject matter which is bound up in one's conceptions of one's and others' faith beliefs.

To further understand the role of collective efficacy and proxy beliefs in the performance of friendship and acquaintances it also important to consider the findings concerning the statistically significant interactions identified in this study and which provide an affirmative answer to the final research question (RQ3 i.e., Are there statistically significant interaction effects involving collective efficacy, proxy efficacy, and group type?). For the subjects of Geography and Religious Studies there appears to be a consistent pattern concerning the nature of the interactions involving collective efficacy and group type. In general, when collective efficacy was low, acquaintance groups scored higher on the 
summative tasks, and when collective efficacy was high, friendship groups scored higher on the summative tasks. Thus, in the context of this study, collective efficacy likely was a salient factor in the performance of friendship groups in Geography and Religious Studies. One explanation is that there may have been differences in the degree of connectedness amongst friends. Although friends tend to have stronger interpersonal affiliations and bonds than acquaintances (Zajac \& Hartup, 1997), it is important to acknowledge that the nature and quality of friendships vary (Berndt, 2002). It is possible that in this study, when connection was low, friendship groups were more likely to have lower collective efficacy, and subsequently, lower performance. On the other hand, when connection was high, friendship groups were likely to have higher collective efficacy, and subsequently, higher performance. The sociometric measure used in this study to identify friendship clusters, focused on reciprocated friendship nominations. Future research may consider sociometric measures that capture not only reciprocated friendship relations but also variability in the degree of connectedness between students in different friendship clusters.

In Religious Studies lower proxy efficacy was associated with higher scores on the group performance tasks, especially when collective efficacy was low. It is important to distinguish between a group characteristic i.e., in this case, proxy efficacy and an emergent group phenomenon (collective efficacy) (Kozlowksi \& Klein, 2000). Although proxy efficacy was measured using means of all proxy efficacy beliefs for each role, the frames of reference were the individual roles, whereas the frame of reference for collective efficacy was the group (i.e., the group perceived capabilities for successfully performing tasks as a group). One may speculate that proxy efficacy and collective efficacy have a complementary relationship. That is, when one is low, the other likely is a stronger predictor of performance. 
This study has limitations that need to be acknowledged. First, the sample comprised participants from a single, all male, Catholic High school. Consequently, the findings of the research have limited generalizability. It would be unwise to assume the results would necessarily apply in a different context. The participating school was chosen as it is one of very few schools in Australia to adopt project-based learning as the main mode of instruction for students in the junior high school years. Future research should explore the role of efficacy beliefs in project-based learning settings with a larger, preferably, random, sample of schools, including non-denominational and co-educational schools. Second, participant constraints mean the study focused on three school subjects with participants from Grade 8 . Future research should include a wider range of subjects including science and math-based subjects, with participants from different grade cohorts in high school. Third, the length of the projects for this study ran for a total of five weeks. Projects can run for longer periods (e.g., 10 weeks). As efficacy beliefs are fluid and changeable, the nature of the relationships involving collective efficacy and proxy efficacy with group performance may be significantly different depending on the length of the project; with projects of varying lengths, it may be worthwhile to model time as a variable. Future research should explore the role of efficacy for projects of longer durations. Fourth, only a limited number of theoretical constructs were used to predict group performance on the summative tasks. It is possible that other constructs, such as self-efficacy, could also predict the performance of friendship and acquaintance groups on project-based assignments. Self-efficacy beliefs may also important to consider when taking into account the nature of group tasks. For example, proxy and collective efficacy did not predict group performance for the poetry task. Given the unique nature of this art form, it is reasonable to expect students to vary in their perceived capabilities (i.e., self-efficacy) for effectively contributing to a group poem. Future studies should incorporate 
the self-efficacy construct alongside the other efficacy constructs, proxy efficacy and collective efficacy.

Despite limitations, this study is one of the first to explore the roles of collective efficacy and proxy efficacy with project-based learning. To date, few studies have included collective efficacy in studies of group work in high school settings, and it is unclear if any studies have included this construct in research on project-based learning or studies on friendship and acquaintance groups. The inclusion of proxy efficacy appears to be new in terms of studies of groups in not only school settings, but also studies of groups more generally. In efficacy-based research studies, higher efficacy beliefs are often assumed to be associated with higher performance outcomes. Although only a single study, the findings from this research suggest that there are likely to be differences in different contexts. 
PROJECT-BASED LEARNING, FRIENDS, EFFICACY BELIEFS

\section{References}

Alavi, S. B., \& McCormick, J. (2016). Implications of proxy efficacy for studies of team leadership in organizational settings. European Psychologist, 21, 218-228.

Alavi, S. B., \& McCormick, J. (2018). Why do I think my team is capable? A study of some antecedents of team members' personal collective efficacy beliefs. Educational Psychology, 38, 1-17.

Azmitia, M., \& Montogmery, R. (1993). Friendship, transactive dialogues, and the development of scientific reasoning. Social Development, 2, 202-201. http://dx.doi.org/10.1111/j.1467-9507.1993.tb00014.x

Baines, E., Blatchford, P., \& Webster, R. (2015). The challenges of implementing group work in primary school classrooms and including pupils with special educational needs. Education, 43, 15-29. http://dx.doi.org/10.1080/03004279.2015.961689

Bandura, A. (1997). Self-efficacy: The exercise of control. New York: Freeman.

Bandura, A. (2000). Exercise of human agency through collective efficacy. Current Directions in Psychological Science, 9, 75-78. http://dx.doi.org/10.1111/1467$\underline{8721.00064}$

Bandura, A. (2001). Social-cognitive theory: An agentic perspective. Annual Review of Psychology, 52, 1-26.

Bandura, A. (2006). Guide to constructing self efficacy scales. In F. Pajares \& T. Urdan (Eds.), Self-efficacy beliefs of adolescents (pp.307-337). Greenwich, CT: Information Age. 
PROJECT-BASED LEARNING, FRIENDS, EFFICACY BELIEFS

Barry, C. M., \& Wentzel, K. R. (2006). Friend influence on prosocial behavior: The role of motivational factors and friendship characteristics. Developmental Psychology, 42, 153-163. http://dx.doi.org/10.1037/0012-1649.42.1.153

Berndt, T. J. (2002). Friendship quality and social development. Current Directions in Psychological Science, 11, 7-10.

Berndt, T. J., Perry, T. B., \& Miller, K. E. (1988). Friends' and classmates' interactions on academic tasks. Journal of Educational Psychology, 80, 506-513. http://dx.doi.org/10.1037/0022-0663.80.4.506

Burk, W. J., \& Laursen, B. (2005). Adolescent perceptions of friendship and their associations with individual adjustment._International Journal of Behavioral Development,29, 156-164. http://dx.doi.org/10.1080/01650250444000342

Chung, S., Lount, R. B., Park, H. M., \& Park, E. S. (2018). Friends with performance benefits: A meta-analysis on the relationship between friendship and group performance. Personality and Social Psychology Bulletin, 44, 63-79. https://doi.org/10.1177/0146167217733069

Finegold, M., \& Eilam, B. (1995). Sociometric analysis: A classroom assessment tool for teachers. Studies in Educational Evaluation, 21, 57-71.

Galton, M. \& Hargreaves, L. (2009). Group work: still a neglected art? Cambridge Journal of Education, 39, 1-6. http://dx.doi.org/10.1080/03057640902726917

Galton, M., Hargreaves, L., \& Pell, T. (2009). Group work and whole-class teaching with 11to 14-year-olds compared. Cambridge Journal of Education, 39, 119-140. http://dx.doi.org/10.1080/03057640802701994 
PROJECT-BASED LEARNING, FRIENDS, EFFICACY BELIEFS

Goddard, R. D., Hoy, W. K., \& Woolfolk Hoy, A. (2004). Collective efficacy beliefs: Theoretical developments, empirical evidence, and future directions. Educational Researcher, 33, 3-13. https://doi.org/10.3102/0013189X033003003

Goncalo, J. A., Polman, E., \& Maslach, C. (2010). Can confidence come too soon? Collective efficacy, conflict and group performance over time. Organizational Behavior and Human Decision Processes, 113, 13-24.

http://dx.doi.org/10.101016/jobhdp.2010.05.001

Gully, S. M., Incalcaterra, K. A., Joshi, A., \& Beaubien, J. M. (2002). A meta-analysis of team-efficacy, potency, and performance: Interdependence and level of analysis as moderators of observed relationships. Journal of Applied Psychology, 87, 819-832.

Hanham, J., \& McCormick, J. (2008). Relationships between self-processes and group processes with friends and acquaintances. Issues in Educational Research, 18, 118137.

Hanham, J., \& McCormick, J. (2009). Group work in schools with close friends and acquaintances: Linking self-processes with group processes. Learning and Instruction, 19, 214-227. http://dx.doi.org/10.1016/j.learninstruc.2008.04.002

Hanham, J., \& McCormick, J. (2018). A multilevel study of self-beliefs and student behaviors in a group problem-solving task. The Journal of Educational Research, 111, 201-212. http://dx.doi.org/10.1080/00220671.2016.1241736

Hanham, J. Ullman, J., Orlando, J., \& McCormick, J. (2014). Intentional learning with technological proxies: Goal orientations and efficacy beliefs. Australian Journal of Education, 58, 36-49. 
PROJECT-BASED LEARNING, FRIENDS, EFFICACY BELIEFS

Hare, A. P. (1994). Types of roles in small groups: A bit of history and a current perspective. Small Group Research, 25, 443-448.

Hartup, W. W. (1996). The company they keep: Friendships and their developmental significance. Child Development, 67, 1-13. http://dx.doi.org/10.2307/1131681

Hartup, W. W. (1998). Cooperation, close relationships, and cognitive development. In W.

M., Bukowski, A. F., Newcomb, W. Hartup, (Eds.), The company they keep:

Friendship in childhood and adolescence. Cambridge studies in social and emotional development (pp. 213-237). Cambridge, UK: Cambridge University Press.

Hartup, W. W., \& Stevens, N. (1997). Friendships and adaptation in the life course. Psychological Bulletin, 121, 355-370. https://doi.org/10.1037/0033-2909.121.3.355.

Hendry, A., Hays, G. , Challinor, K. , \& Lynch, D. (2017). Undertaking educational research following the introduction, implementation, evolution, and hybridization of constructivist instructional models in an Australian PBL High

School. Interdisciplinary Journal of Problem-Based Learning, 11(2).

https:// doi.org/10.7771/1541-5015.1688

Henrich, C. C., Kuperminc, G. P. Sack, A., Blatt, S. J., \& Leadbeater, B. J. (2000). Characteristics and homogeneity of early adolescent friendship groups: A comparison of male and female clique and non-clique members. Applied Developmental Science, 4, 15-26. http://dx.doi.org/10.1207/S1532480XADS0401_2

Jehn, K., \& Shah, P. P. (1997). Interpersonal relationships and task performance: An examination of mediating processes in friendship and acquaintance groups. Journal of Personality and Social Psychology, 72, 775-790. http://dx.doi.org/10.1037/00223514.72.4.775 
PROJECT-BASED LEARNING, FRIENDS, EFFICACY BELIEFS

Khong, J. Z. N., Liem, G. A. D., \& Klassen, R. M. (2017). Task performance in small group settings: the role of group members' self-efficacy and collective efficacy and group's characteristics, Educational Psychology, 37:9, 1082-1105. http://dx.doi.org/ $10.1080 / 01443410.2017 .1342767$

Kozlowski, S. W. J., \& Klein, K. J. (2000). A multilevel approach to theory and research in organizations: Contextual, temporal, and emergent processes. In K. J. Klein \& S. W. J. Kozlowski (Eds.), Multilevel theory, research, and methods in organizations: Foundations, extensions, and new directions (pp. 3-90). San Francisco, CA, US: Jossey-Bass.

Ladd, G. W., \& Emerson, E. S. (1984). Shared knowledge in children's friendships. Developmental Psychology, 20, 932-940.

McDonald, R. P. (1999). Test theory: A unified treatment. Mahwah, NJ: Lawrence Erlbaum

McCormick, J., Alavi, S. B., \& Hanham, J. (2015). The importance of context when applying social cognitive theory in organizations. In A. Ortenbald (Ed.), Handbook of research on management ideas and panaceas: Adaptation and context. Publisher: Edward Elgar.

Miell, D., \& MacDonald, R. A. R. (2000). Children's creative collaborations: The importance of friendship when working together on a musical composition. Social Development, 9, 348-369. http://dx.doi.org/10.1111/1467-9507.00130

Mitchell, S. N., Reilly, R., Bramwell, F. G., Solonksy, A., \& Lilly, F. (2004). Friendship and choosing groupmates: Preference for teacher-selected vs. student-selected groupings in high school science classes. Journal of Instructional Psychology, 31, 20-32. 
PROJECT-BASED LEARNING, FRIENDS, EFFICACY BELIEFS

Newcomb, A. F., \& Bagwell, C. L. (1995). Children's friendship relations: A meta-analytic review. Psychological Bulletin, 117, 306-347. http://dx.doi.org/10.1037/0033$\underline{2909.117 .2 .306}$

Pedhazur, E. J. (1982). Multiple regression in behavioral research: Explanation and prediction (Second Ed.). New York: Holt, Rinehart, and Winston.

Rubin, K. H., Bukowski, W. M., \& Parker, J. G. (2006). Peer interactions, relationships, and groups. In W. Damon \& R. M. Lerner (Series Eds.) \& N. Eisenberg (Vol. Ed.), Handbook of child psychology, Vol. 3, Social, emotional, and personality development (6 $6^{\text {th }}$ ed., 571-645), New York: Wiley.

Savery, J. R. (2006). Overview of Problem-based Learning: Definitions and Distinctions. Interdisciplinary Journal of Problem-Based Learning, 1(1). https://doi.org/10.7771/1541-5015.1002

Stajkovic, A. D., Lee, D., \& Nyberg, A. J. (2009). Collective efficacy, group potency and group performance: Meta-analyses of their relationships and test of a mediation model. Journal of Applied Psychology, 94, 814-828.

Stegmueller, D. (2013). How many countries for multilevel modeling? A comparison of frequentist and Bayesian approaches. American Journal of Political Science, 57, 748761.

Swenson, L. M., \& Strough, J. (2008). Adolescents' collaboration in the classroom: do peer relationships orgender matter? Psychology in the Schools, 45(8), 715-728. https://doi.org/10.1002/pits.20337. 
Wentzel, K. R., Barry, C. M., \& Caldwell, K. (2004). Friendships in middle school: Influences on motivation and school adjustment. Journal of Educational Psychology, 96, 195-203.

Wentzel, K. R., Jablansky, S., \& Scalise, N. R. (2018). Do friendships afford academic benefits? A meta-analytic study. Educational Psychology Review, 30, 1241-1267 https://doi.org/10.1007/s10648-018-9447-5

Wang, S. L., \& Hwang, G. J. (2012). The role of collective efficacy, cognitive quality, and task cohesion in computer-supported collaborative learning. Computers \& Education, 58, 679-687. http://dx.doi.org/10.1016/j.compedu.2011.09.003

Webb, N. M., \& Mastergeorge, A. (2003). Promoting effective helping behavior in peerdirected groups. International Journal of Educational Research, 39, 73-79.

Webb, N. M., \& Palincsar, A. S. (1996). Group processes in the classroom. In D. Berliner \& R. Calfee (Eds.), Handbook of educational psychology ( $3^{\text {rd }}$ ed., pp. 841-873). New York: Macmillan.

Zajac, R. J., \& Hartup, W. W. (1997). Friends as co-workers: Research review and classroom implications. Elementary School Journal, 98, 3-13. http://dx.doi.org/10.1086/461881

\section{Appendix A.}

$\underline{\text { Table A1 Excerpts from Rubrics Showing Criteria for Summative Tasks (video) for Projects used in }}$ this Study.

\begin{tabular}{|c|c|c|c|}
\hline$\frac{\text { CRITERIA }}{\text { Marks* }}$ & $\frac{\text { BASIC }}{1-2-3-4}$ & $\frac{\text { COMPETENT }}{\underline{5-6-7}}$ & $\frac{\text { ADVANCED }}{\underline{8-9-10}}$ \\
\hline$\frac{\frac{\text { Religious Studies }}{\text { Covenant Animated }}}{\text { (whiteboard) }}$ & $\begin{array}{l}\text { - Uses a surface } \\
\frac{\text { other than a }}{\text { whiteboard for the }}\end{array}$ & $\begin{array}{l}- \text { Uses a whiteboard } \\
\frac{\text { for the video }}{\text { Creates a }}\end{array}$ & $\begin{array}{l}\text { Finds creative } \\
\frac{\text { ways to use a }}{\text { whiteboard for the }}\end{array}$ \\
\hline
\end{tabular}




\begin{tabular}{|c|c|c|c|c|}
\hline$\frac{\text { Video Production }}{\underline{\text { (Group task })}}$ & 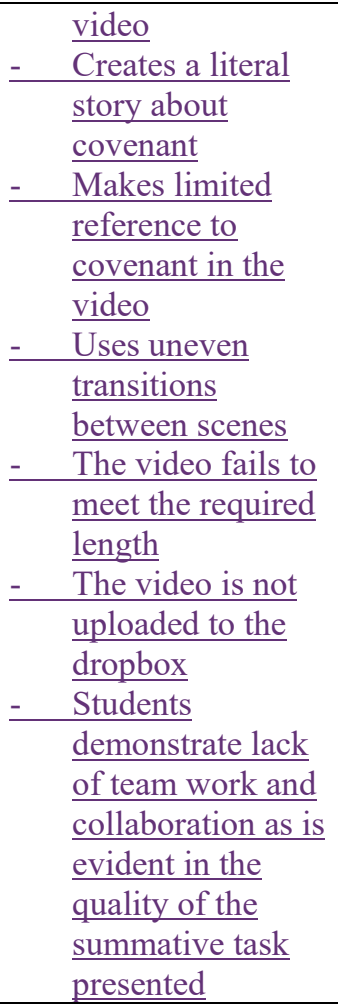 & 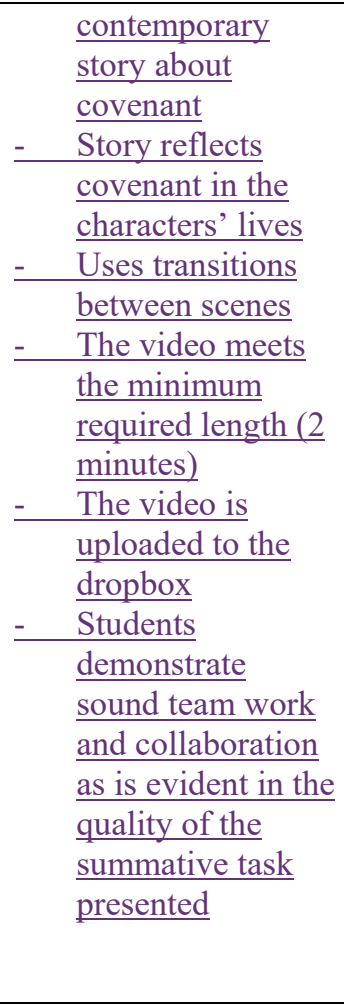 & - & $\begin{array}{l}\text { video } \\
\text { Creates a } \\
\text { contemporary, } \\
\text { interesting story } \\
\text { about covenant } \\
\text { Story reflects } \\
\text { clearly covenant } \\
\text { in the characters' } \\
\text { lives } \\
\text { Uses smooth or } \\
\text { innovative } \\
\text { transitions } \\
\text { between scenes } \\
\text { The video meets } \\
\text { the minimum (2 } \\
\text { mins.) required } \\
\text { length but does } \\
\text { not exceed the } \\
\text { maximum (4 } \\
\text { mins.) } \\
\text { The video is } \\
\text { uploaded to the } \\
\text { dropbox as } \\
\text { Quicktime, MP4 } \\
\text { or AVI file. }\end{array}$ \\
\hline $\begin{array}{c}\frac{\text { Geography }}{\text { Globalisation Panel }} \\
\frac{\text { Discussion }}{\text { Video Production }} \\
\underline{\text { (Group task })}\end{array}$ & 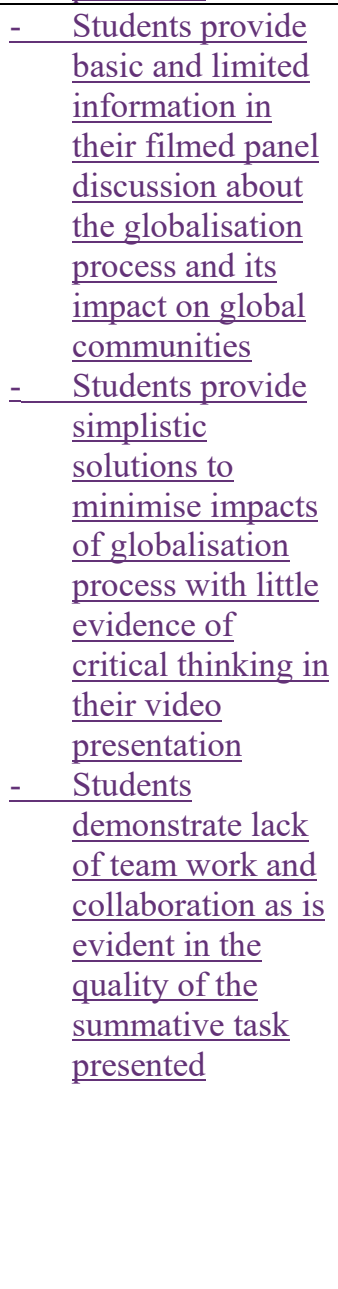 & 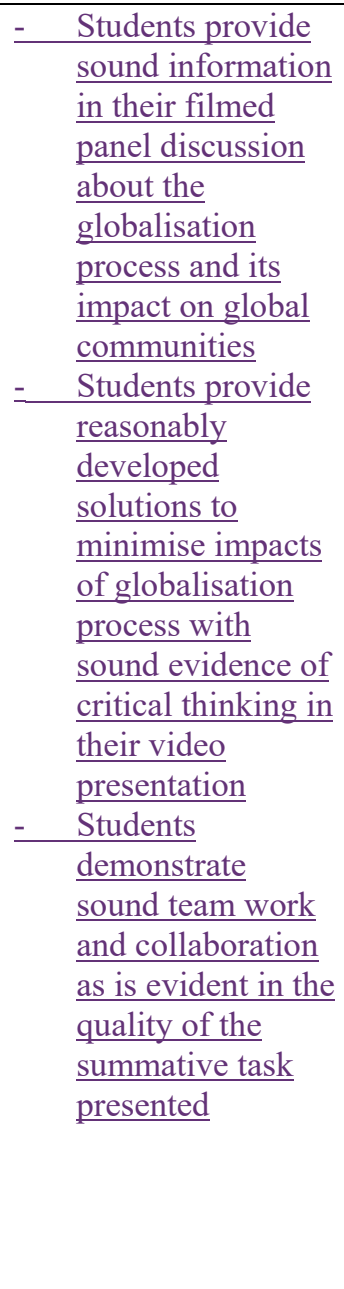 & - & 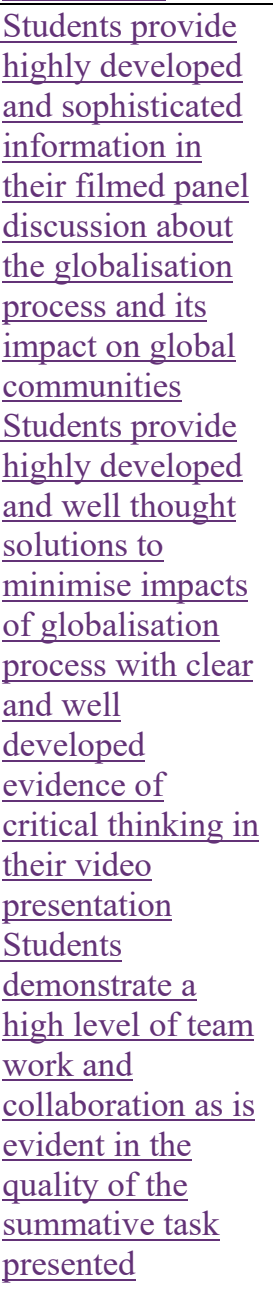 \\
\hline$\frac{\text { English }}{\text { Poetry }}$ & $\begin{array}{ll}- & \text { Group constructed } \\
\text { poem }\end{array}$ & $\begin{array}{l}\text { - } \quad \text { Group constructed } \\
\text { poem }\end{array}$ & - & $\begin{array}{l}\text { Group constructed } \\
\text { poem }\end{array}$ \\
\hline
\end{tabular}




\begin{tabular}{|c|c|c|c|}
\hline$\frac{\text { Video Production }}{\text { (Group task) }}$ & 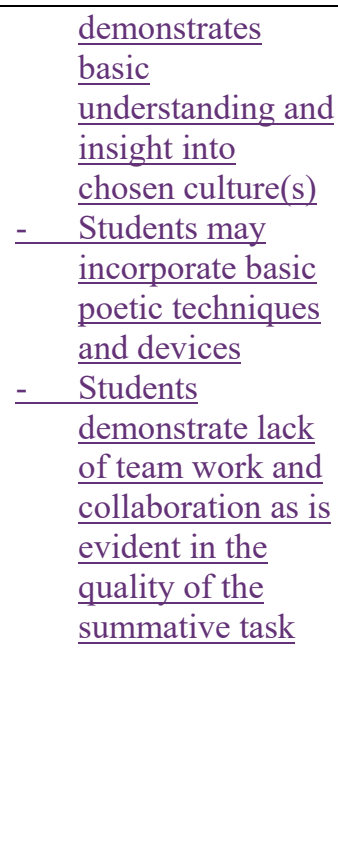 & $\begin{array}{l}\frac{\text { demonstrates }}{\text { Sound }} \\
\frac{\text { understanding and }}{\text { insight into }} \\
\begin{array}{l}\text { chosen culture(s) } \\
\text { Students }\end{array} \\
\begin{array}{l}\text { incorporate some } \\
\text { poetic techniques }\end{array} \\
-\frac{\text { and devices }}{\text { Students }} \\
\underline{\text { demonstrate }} \\
\underline{\text { sound team work }} \\
\text { and collaboration } \\
\begin{array}{l}\text { as is evident in the } \\
\text { quality of the }\end{array} \\
\text { summative task } \\
\text { presented }\end{array}$ & 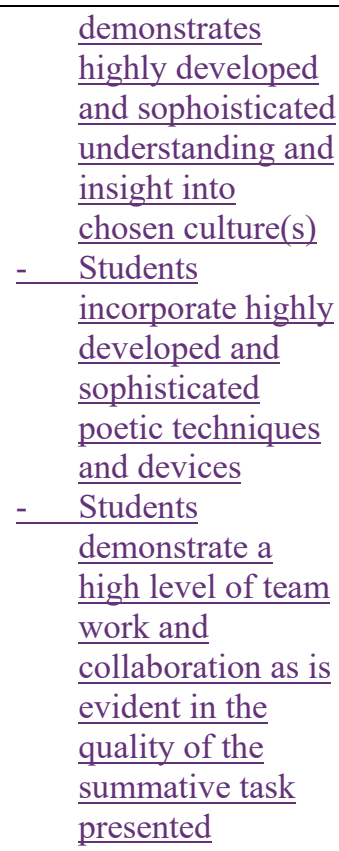 \\
\hline
\end{tabular}

$\underline{\text { Table A2. Rubric for video production across all projects }}$

\begin{tabular}{|c|c|c|c|}
\hline CRITERIA & BASIC & COMPETENT & ADVANCED \\
\hline $\begin{array}{l}\text { Video Production } \\
\text { (Generic rubric. } \\
\text { Elements of which } \\
\text { incorporated into } \\
\text { project rubrics) } \\
\text { Teacher to select } \\
\frac{\text { what is appropriate }}{\text { for their project }}\end{array}$ & 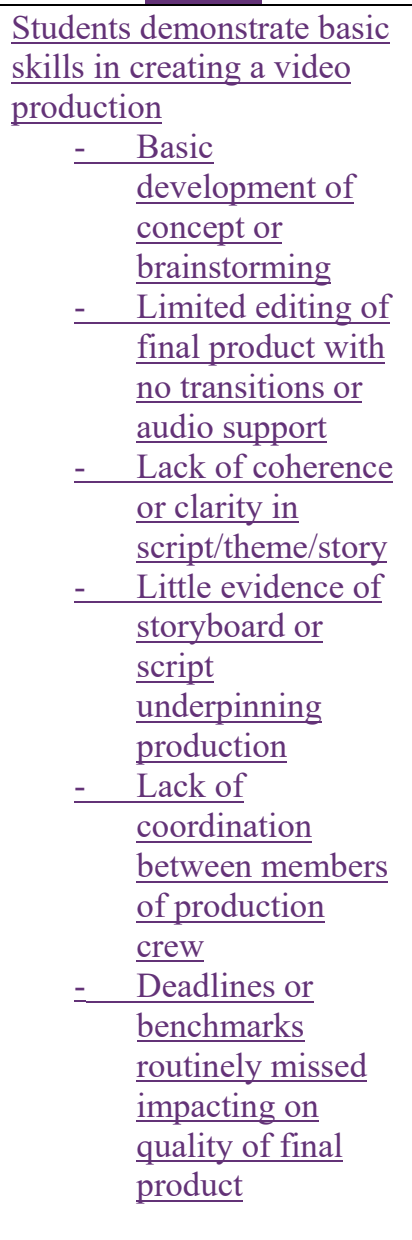 & 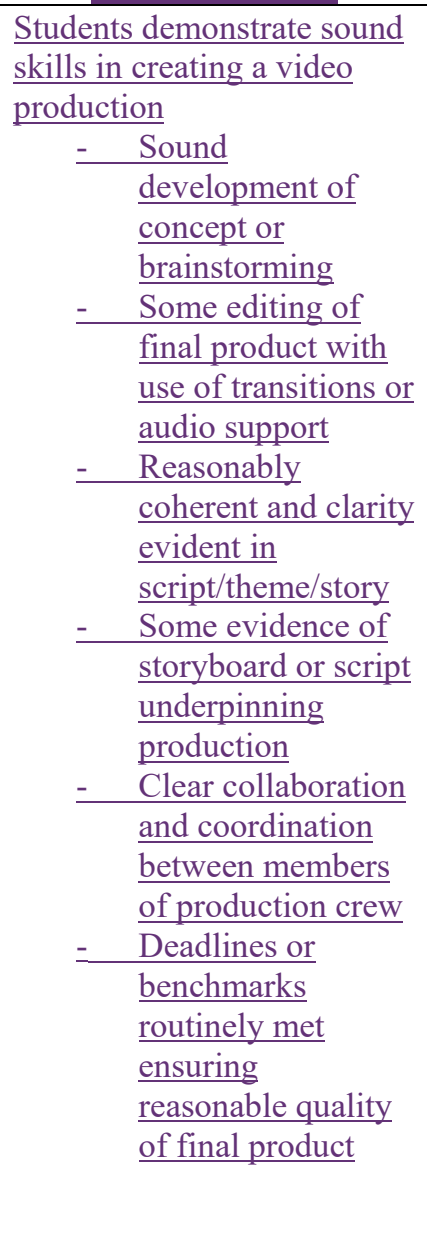 & 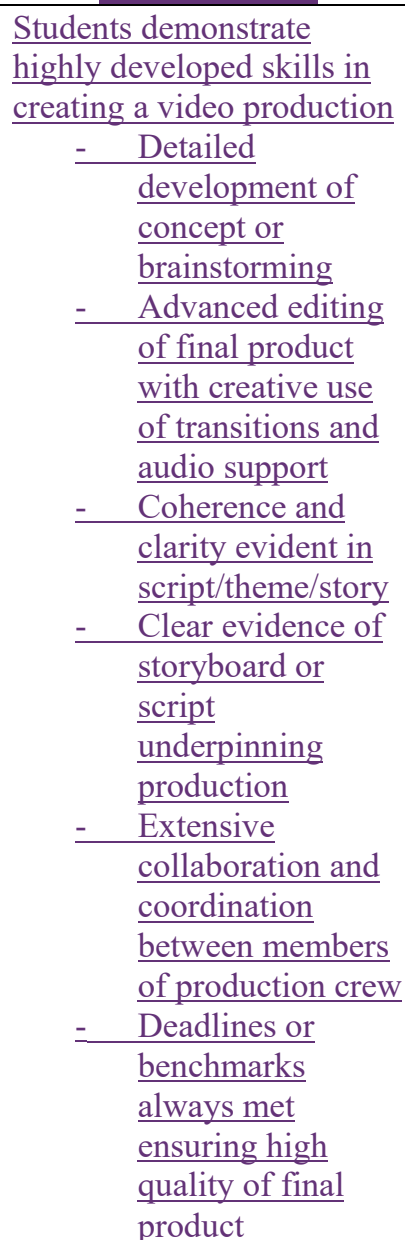 \\
\hline
\end{tabular}


PROJECT-BASED LEARNING, FRIENDS, EFFICACY BELIEFS 